\title{
UN NUEVO ENFOQUE DE LA AUDITORIA INTEGRAL PARA SU APLICACIÓN EN EL PERÚ
}

Dr. ERNESTO A. POLAR FALCÓN.(*)

En la última década del pasado Siglo $\mathrm{XX}$, los auditores que en una u otra forma, brindaban sus servicios profesionales de Auditoría a las empresas privadas e instituciones del Estado, recibieron con verdadero interés las primeras expresiones de lo que hoy en día se llama Auditoría Integral.

Desde un punto de vista analítico, en el Perú, ya se han aplicado las técnicas de la Auditoría Integral, a partir de la segunda mitad del Siglo XX, sin que se le denominara Auditoría Integral; simplemente se ofrecían los servicios de Auditoría Financiera, cuyo objetivo era presentar el Dictamen, en base a una planificación para los cinco o seis primeros meses del año calendario; y luego buscar fuentes de trabajo, para los últimos seis o siete meses del año calendario, que facilitaran la obtención de ingresos suficientes para cubrir los costos de personal y administración, tanto para las oficinas de auditores independientes como para las oficinas de sociedades de auditoría aebidamente constituidas en el Perú.

Las fuentes de trabajo que los a_ditores ofrecían en épocas alternativas con a Auditoría Financiera, son consideradas ¿ $\rightarrow a$ la fecha como Auditoría no Financieras; a las cuales el C.P. Yanel Blanco Luna, en su libro titulado "Normas y Procedimientos de la Auditoria Integral", publicado en febrero de 1998 las denomina Auditorías: de Cumplimiento, de Actuación, de Economía y Eficiencia, de Programa, Operacional, Administrativa, Operativa de Sistemas, de Gestión de Calidad, de Performance, etc.

De lo que se deduce, que la Auditoría Financiera, siempre ha sido considerada como la especialidad más importante de lo que se llama Auditoría General o simplemente Auditoría.

La mayoría de auditores que a la fecha, ofrecen sus servicios profesionales en el Perú, estudiaron y practicaron la Auditoría Financiera en las sucursales de las sociedades de auditoría transnacionales o en las sociedades de auditoría que tienen la representación de una sociedad del exterior; y para ellos, realizar el examen de los Estados Financieros de una empresa privada o de una institución estatal, hasta culminar con el respectivo Dictamen, así como presentar posteriormente. la Carta de Recomendaciones de Control Interno, que conducía a desarrollar trabajos adicionales, mucho de los cuales tienen los nombres que

- Docente Principal de la Facultad de Ciencias Contables de la UNMSM. 
anota el libro mencionado, eran procedimientos normales de servicios de Auditoría Financiera y otros servicios integrales, que se desarrollaban en el transcurso de los doce meses del año calendario.

El C.P. Yanel Blanco Luna, dice en la "Introducción" de su libro lo siguiente:

"Toda esta proliferación de auditorías se puede interpretar como un campanazo de alerta para las auditorías financiera e interna tradicionales, en el sentido de que sus objetivos y alcances no satisfacen las necesidades y los usuarios principales de la información: administradores, inversionistas, gobiernos y la comunidad en general.

Si se tiene en cuenta que el alcance de una Auditoria Financiera, toca aspectos de las auditorías no financieras con alcances, desde luego, más limitados y para evitar que las empresas se llenen de especialistas en algo que podría ser suministrado en un servicio integral del Contador Público, que desarrolla la Auditoría Financiera, se propone en este trabajo el proceso de una auditoría desarrollada por el Contador Público independiente que responda a las necesidades crecientes de los usuarios de la información y a esta auditoría la hemos denominado Auditoría Integral.

La Auditoría Integral, implica la ejecución de un trabajo con el alcance o enfoque, por analogía, de las auditorias financiera, de cumplimiento, de control interno y de gestión. La Auditoría Integral es un modelo de cobertura global y por lo tanto, no se trata de una suma de auditorías. "."

Analizando el contenido profesional del libro titulado "Normas y Procedimientos de la Auditoria Integral", el autor del presente artículo está de acuerdo con la siguiente definición dada sobre Auditoría Integral:

"Es el proceso de obtener y evaluar objetivamente, en un período determinado, evidencia relativa a la información financiera, al comportamiento económico y al manejo de una entidad, con el propósito de informar sobre el grado de correspondencia entre aquellos y los criterios o indicadores establecidos o los comportamientos generalizados".
Asimismo, es destacable mostrar que el autor del mencionado libro, precisa que la Auditoría Integral, es un modelo de cobertura global y por lo tanto, no se trata de una suma de auditorias y que para fines metodológicos presenta la siguiente estructura:

\section{AUDITORÍA INTEGRAL:}

- Auditoría Financiera

- Auditoría de Cumplimiento o de Legalidad

- Auditoría de Gestión:

- Auditoría de Eficiencia

- Auditoría de Eficacia

- Auditoria de Economía

\section{- Auditoría de Control Interno}

En base a la lectura metodológica presentada, estamos de acuerdo con los cuatro siguientes objetivos planteados por el C.P. Yanel Blanco Luna, en su libro, que definen prácticamente la operatividad de esta estructura:

a. Expresar una opinión sobre si los estados financieros objetos del examen, están preparados en todos los asuntos importantes de acuerdo con las normas de contabilidad y de revelaciones que le son aplicables.

Este objetivo tiene el propósito de proporcionar una certeza razonable de que los estados financieros, finales o intermedios, tomados de forma integral están libres de manifestaciones erróneas importantes. Certeza razonable es un término que se refiere a la acumulación de la evidencia de la auditoria necesaria para que el auditor concluya que no hay manifestaciones erróneas substanciales en los estados financieros tomados en forma integral.

b. Establecer si las operaciones financieras, administrativas, económicas y de otra índole se han realizado conforme a las normas legales, reglamentarias estatutarias y de 
procedimientos que le son aplicables. El propósito de esa revisión es proporcionar al auditor una certeza razonable si las operaciones de la entidad se conducen de acuerdo con las leyes y reglamentos que las rigen.

c. Si la entidad se ha conducido de manera ordenada en el logro de las metas y objetivos propuestos. El grado en que la administración ha cumplido adecuadamente con las obligaciones y atribuciones que han sido asignadas y si tales funciones se han ejecutado de manera eficiente, efectiva $y$ económica.

d. Evaluar el sistema global del control interno para determinar si funciona efectivamente para la consecución de los siguientes objetivos básicos:

- Efectividad y eficiencia de las operaciones.

- Confiabilidad en la información financiera.

- Cumplimiento de las leyes y regulaciones aplicables.

Ahora, veamos el concepto de cada una de las cuatro divisiones de la Auditoría Integral, así como los comentarios que se derivan de dichos conceptos.

La Auditoría Financiera, se define así:

"La auditoría financiera tiene como objetivo la revisión o examen de los estados finacieros por parte de un auditor distinto del que preparó la información contable y del _suario, con la finalidad de establecer su acionalidad, dando a conocer los resultados de su examen, a fin de aumentar la utilidad oue la información posee. El informe o sictamen que presenta el auditor otorga fe oublica a la confiabilidad de los estados I nancieros, y por consiguiente, de la sredibilidad de la gerencia que los preparó.

La opinión o dictamen del auditor, - nda crédito a las manifestaciones o vlaraciones de la administración de entidad aumenta la confianza en tales manifes- taciones aunque no la torna absoluta. El auditor no es un asegurado en un proceso de auditoría por cuanto los mismos estados financieros no son seguros ni exactos, sino solamente razonables. La seguridad total no se logra ni en la contabilidad ni en la auditoría, debido a factores tales como: La aplicación de criterio, el uso del muestreo y limitaciones inherentes al control interno".

\section{COMENTARIOS}

1. En el Perú, el Contador Público esta autorizado a ejercer la Auditoría Integral, de acuerdo a la Ley $\mathrm{N}^{\circ} 13253$ Ley de Profesionalización del Contador Público que dice:

"ARTíCULO 4to.- Corresponde a los Contadores Públicos efectuar y autorizar toda clase de balances, peritajes y tasaciones de su especialidad, operaciones de auditoría y estudios contables con fines judiciales $y$ administrativos".

2. El Contador Público que desea ofrecer servicios de Auditoría, tiene que inscribirse en el "Reglamento para el Ejercicio de la Auditoría Independiente" del Colegio de Contadores Públicos de Lima.

3. Los Contadores Públicos que tienen una Sociedad de Auditoría, deben registrarla en el "Registro Único de Sociedades de Auditoría-RUNSA", en cumplimiento del Decreto Legislativo $\mathrm{N}^{\circ} 850$ y el Decreto Supremo $N^{\circ}$ 137-96-EF-Normas Complementarias y Reglamento del Decreto Legislativo $\mathrm{N}^{\circ} 850$.

4. Los Contadores Públicos que desean ofrecer sus servicios como Auditores Independientes, tienen que inscribirse en los Registros de Auditores Independientes de la Comisión 
Nacional Supervisora de Empresas y Valores-CONASEV.

\section{La Auditoría de Cumplimiento se define así:}

"La Auditoría de Cumplimiento es la comprobación o examen de operaciones financieras, administrativas, económicas y de otra índole de una entidad para establecer que se han realizado conforme a las normas legales, reglamentarias, estatutarias y de procedimientos que le son aplicables.

Esta auditoría se practica mediante la revisión de documentos que soportan legal, técnica, financiera y contablemente las operaciones para determinar si los procedimientos utilizados y las medidas de control interno están de acuerdo con las normas que le son aplicables y si dichos procedimientos están operando de manera efectiva y son adecuados para el logro de los objetivos de la entidad".

\section{COMENTARIOS}

1. Las técnicas y procedimientos de la Auditoría de Cumplimiento se pueden aplicar en el Perú, en las siguientes especialidades:

- Auditoría Interna

- Auditoría Tributaria

- Auditoría Gubernamental

- Auditoría Informática

- Auditoría Operacional

2. En estas especialidades, la Auditoría de Cumplimiento cumple con el objetivo de comprobar o examinar las operaciones en general, según sus propios objetivos y proceder a informar si se están cumpliendo con las normas legales reglamentarias, estatutarias y de procedimientos que se han dado.
3. El Contador Público tiene las aptitudes para ejecutar la Auditoría de Cumplimiento, sin requerir registro alguno en las dependencias públicas, como una nueva fuente de trabajo profesional.

La Auditoría de Gestión se define así:

"La Auditoría de Gestión es el examen que se efectúa a una entidad por un profesional extemo e independiente, con el propósito de evaluar la eficacia de la gestión en relación con los objetivos generales; su eficacia como organización y su actuación y posicionamiento desde el punto de vista competitivo, con el propósito de emitir un informe sobre la situación global de la misma y la actuación de la dirección".

\section{COMENTARIOS}

1. Las técnicas y procedimientos de la Auditoría de Gestión se pueden aplicar en el Perú, en las siguientes especialidades:

- Auditoría Interna

- Auditoría Tributaria

- Auditoría Gubernamental

- Auditoría Informática

- Auditoría Operacional

- Auditoría de Gestión propiamente dicha

2. En estas especialidades, la Auditoría de Gestión cumple con el propósito de evaluar la eficacia y la eficiencia, tal como se describen en la definición de la especialidad.

3. El Contador Público, tiene también las aptitudes necesarias para ejecutar estas especialidades en función de la auditoría de gestión. Quizás requiera un reforzamiento profesional en el entrenamiento de las técnicas de evaluación y análisis ya desarrolladas y de gran difusión a 
nivel de la profesión contable. Es una inagotable fuente de trabajo profesional.

\section{La Auditoría de Control Interno se} define así:

"La Auditoría de Control Interno es la evaluación de los sistemas de contabilidad y de control interno de una entidad, con el propósito de determinar la calidad de los mismos, el nivel de confianza que se les puede otorgar y si son eficaces y eficientes en el cumplimiento de sus objetivos. Esta evaluación tendrá el alcance necesario para dictaminar sobre el control interno y por lo tanto, no se limita a determinar el grado de confianza que pueda conferírsele para otros propósitos".

\section{COMENTARIOS}

1. La Auditoría de Control Interno, es la base y el sustento del alcance de los trabajos de auditoría Financiera y de la Auditoria de Gestión. Si no se aplican las técnicas de revisión de Control Interno en la planificación y ejecución de la auditoría Financiera, no se podría medir el alcance del trabajo a efectuarse. Si no se aplican las técnicas de revisión de Control Interno en la evaluación de los procedimientos operativos de una empresa, no se podría medir la eficiencia y la eficacia de su sistema administrativo y contable en general.

2. El Contador Público, debe aplicar la Auditoría de Control Interno en sus actividades profesionales y ser un experto en la evaluación del Control Interno, tanto en el desarrollo de su trabajo de Contador de una empresa, como en su condición de Auditor; terminando así también una fuente de trabajo permanente.
Esperamos contribuir con la mayor difusión de las partes o áreas de la Auditoría Integral, buscando siempre alcanzar los objetivos de difusión que se merece. 